\title{
Measuring the impact of the COVID-19 lockdown on crime in a medium-sized city in China
}

\author{
Peng Chen ${ }^{1}$ • Justin Kurland ${ }^{2}$ - Alex R. Piquero ${ }^{3,4} \cdot$ Herve Borrion $^{5}$
}

Accepted: 17 August 2021

(C) The Author(s), under exclusive licence to Springer Nature B.V. 2021, corrected publication 2021

\begin{abstract}
Objectives The study examines thevariation in the daily incidence of eight acquisitive crimes: automobile theft,electromobile theft, motorcycle theft, bicycle theft, theft from automobiles,pickpocketing, residential burglary, and cyber-fraud before the lockdown andthe duration of the lockdown for a medium-sized city in China.

Methods Regression discontinuity intime (RDiT) models are used to test the effect of the lockdown measures oncrime by examining the daily variation of raw counts and rate. Results It is indicated that incontrast to numerous violent crime categories such as domestic violence wherefindings have repeatedly found increases during the COVID-19 pandemic,acquisitive crimes in this city were reduced during the lockdown period for allcategories, while "cyber-fraud" was found more resilient in the sense that itsdecrease was not as salient as for most other crime types, possibly due topeople's use of the internet during the lockdown period.

Conclusions The findings providefurther support to opportunity theories of crime that are contingent upon theneed for a motivated offender to identify a suitable target in physical space.
\end{abstract}

Peng Chen

chenpeng@ppsuc.edu.cn

Justin Kurland

justin.kurland@usm.edu

Alex R. Piquero

axp1954@miami.edu

Herve Borrion

h.borrion@ucl.ac.uk

1 School for Informatics Cyber Security, People's Public Security University of China, Beijing, People's Republic of China

2 School of Criminal Justice, Forensic Science, and Security, The University of Southern Mississippi, Hattiesburg, USA

3 Department of Sociology \& Criminology, University of Miami, 5202 University Drive, Merrick Building, Coral Gables, FL 33124, USA

4 Criminology, Monash University, Melbourne, Australia

5 Department of Security and Crime Science, University College London, London, UK 
Keywords COVID-19 $\cdot$ Crime $\cdot$ Regression discontinuity in time $\cdot$ Natural experiment $\cdot$ Routine activities

\section{Introduction}

The COVID-19 pandemic and restrictions put in place to control the spread of the disease have deeply affected human society. Many governments around the world have invoked stay-at-home/shelter-in-place or lockdown orders that have disrupted typical individual-level routine activities that shape the rhythm of society. Public activities have been cancelled, schools and companies closed, and only those businesses deemed essential to maintaining basic human needs such as supermarkets remained opened. Though the spread of the virus has not yet ceased as vaccinations race against variants, the loosening of restrictions, and people's general feeling of being "done" with the pandemic, there is a need to assess the impact of the pandemic and associated restrictions in order to more readily allocate public safety resources and to also better understand the underlying mechanisms responsible for influencing crime patterns and to prepare for future events (Piquero \& Kurland, 2021).

The pandemic provided a historic chance to test environmental criminology. Since changes in crime patterns were observed globally (Boman \& Mowen, 2021; Nivette et al., 2021), criminologists became interested in better understanding these trends and their potential causes. Theories that were focused on the patterning of crime events, especially routine activity theory (Cohen \& Felson, 1979), received extensive attention. Extant research shows that the introduction of pandemic-related restrictions (e.g., social distancing, stay-at-home orders, and lockdowns) was followed by reduction in property crime, assault, drug, organized crime, and cybercrime in various countries including the USA, Mexico, Sweden, UK, Australia, New Zealand, and Indonesia (Abrams, 2021; Campedelli et al., 2020; Estévez, 2021; Gerell et al., 2020; Kim \& Leung, 2020; Kirchmaier \& Villa, 2020; McDonald \& Balkin, 2020; Miyar et al., 2021; Mohler et al., 2020; Payne \& Morgan, 2020; Payne et al., 2021; Syamsuddin et al., 2021). Borrion et al. (2020) proposed a resilience assessment tool to measure the impact of COVID-19 on crime and demonstrated it using data on commercial theft in one Chinese city. Besides this, there has been limited research on this topic in China, the country that had first experienced the outbreak. Broadening this investigation to other crime is, however, critical since China was the first country to implement drastic measures to control the spread of the disease. Doing so would offer the field an important comparison and complement to the growing knowledge base in this space.

The current paper seeks to take advantage of the known, drastic nature of the lockdown in China to evaluate how crime levels were impacted. In what follows, we review extant work that has applied crime pattern/routine activity theory to crime during COVID-19-related lockdowns and then extend this work to the Chinese context. Following, we highlight the data and methodological framework that extend prior research in important ways, and provide analyses focused on describing changes in crime between the period prior to, and during 
the lockdown. Results from the study are discussed along with their relevance to theory, the practice of policing during the pandemic, and policy. We conclude with an acknowledgement of some of the limitations associated with the study and some ideas for similar studies that should be undertaken in the future to better understand the effect, if any, of COVID-19, related lockdowns, and crime.

\section{Initial studies of crime during the COVID-19 era}

As hypothesized by routine activity theory, the risk of crime increases with the convergence of suitable targets, motivated offenders, and the absence of capable guardians (Cohen \& Felson, 1979). The pandemic and governmental restrictions aimed at slowing the spread of the virus, however reshaped people's daily lives and disrupted people's routine behaviors, which caused the crime opportunity structures to change by crime types, time, and place (Stickle \& Felson, 2020). Across crime types, it was believed that theft would be impacted the most in the wake of the pandemic because many stores, restaurants, and shopping centers were closed during initial lockdowns, but that there may still exist variability in crime changes within the larger theft category. For example, shoplifting might decline to a moderate level as many retail stores closed and opportunities were subsequently concentrated in the more "essential" stores like grocers and convenience stores. Pickpocketing would experience a great curtail as compulsory stay-at-home orders required people not leave their accommodations, thus reducing the opportunities available to crowd-dependent offenders.

The second impact of the pandemic and related lockdowns on crime from a routine activity perspective lies on the temporal shift. The restrictions forcing people to stay at home disrupted their routines, meaning that traditional temporal patterns (e.g., differences between workdays and weekdays) were less noticeable in people's activities. As a result, crime was no longer expected to follow the same temporal patterns as before the pandemic. More importantly, as public activities were cancelled and people were forced to stay at home, the overall offending opportunity in time diminished and a drop in crime would likely occur after the restrictions were implemented.

The third potential change generated by the pandemic and the restrictions concerns the location of crime opportunities. The restrictions limiting people's daily activities are believed to have greatly affected the flow of potential offenders, victims, targets and guardians, and their convergence in physical space. Conversely, greater concentration may have taken place in "cyber places." During the pandemic period, people are believed to have spent more time on the internet than before (Buil et al., 2021)—especially during the lockdown periods, which could certainly increase the probability of cybercrime, especially as this might involve visiting new (and potentially hacked) websites, interacting with strangers on fora, making online payments, etc.

The predictions made on the basis of routine activity theory have been supported by a number of empirical studies. Table 1 provides a summary of studies focusing on a quantitative description of crime variation by the type of crime, temporal period, 


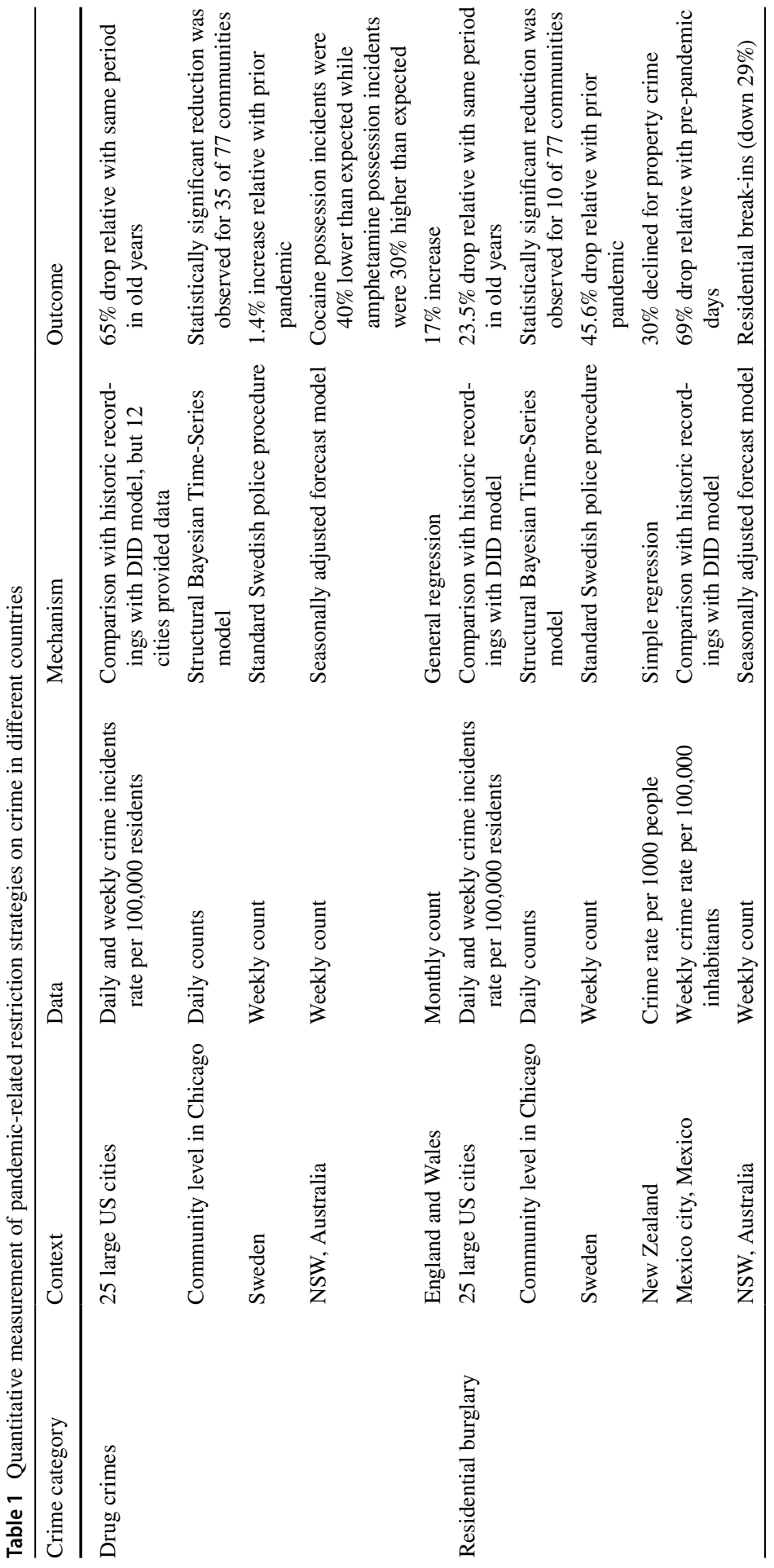




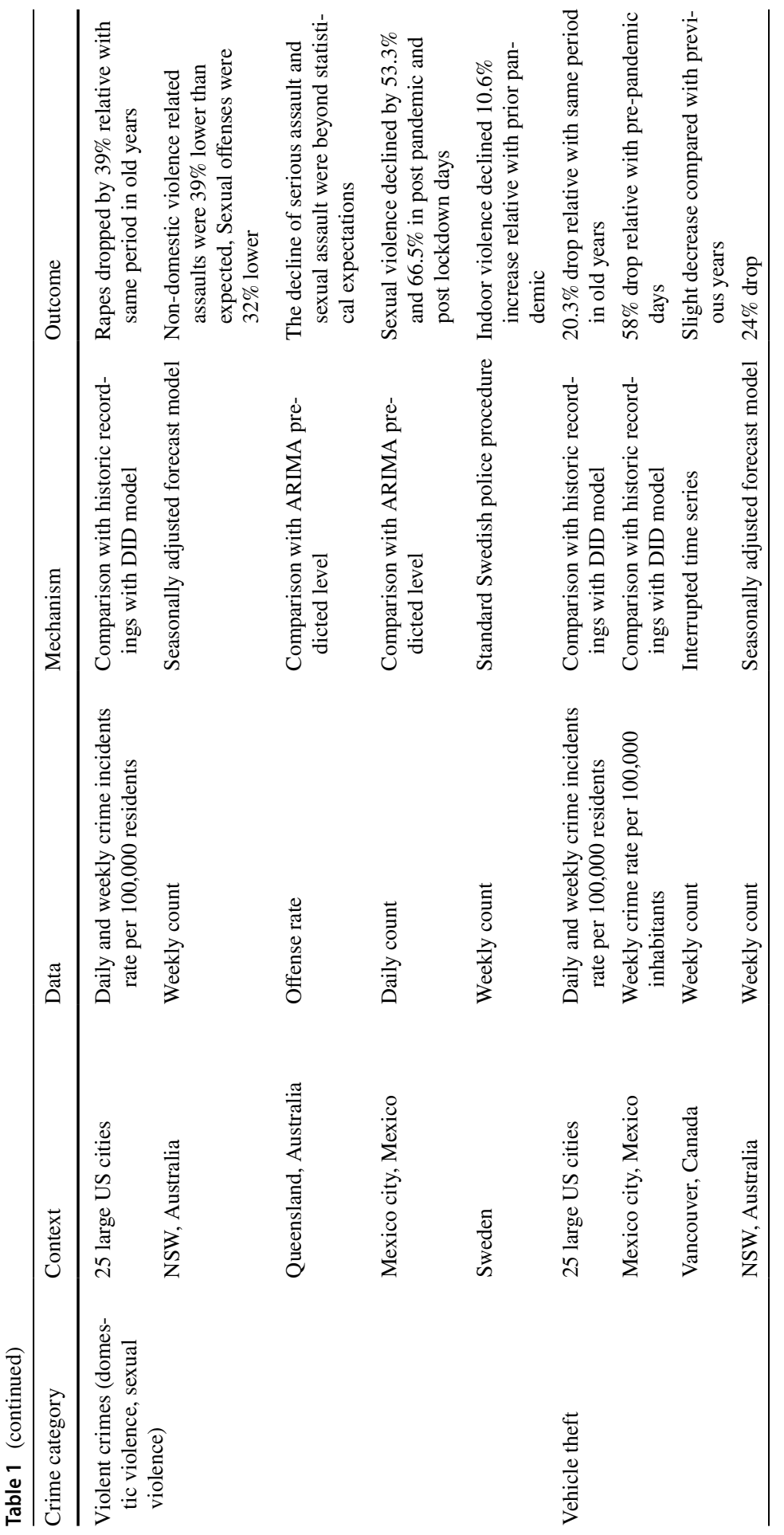




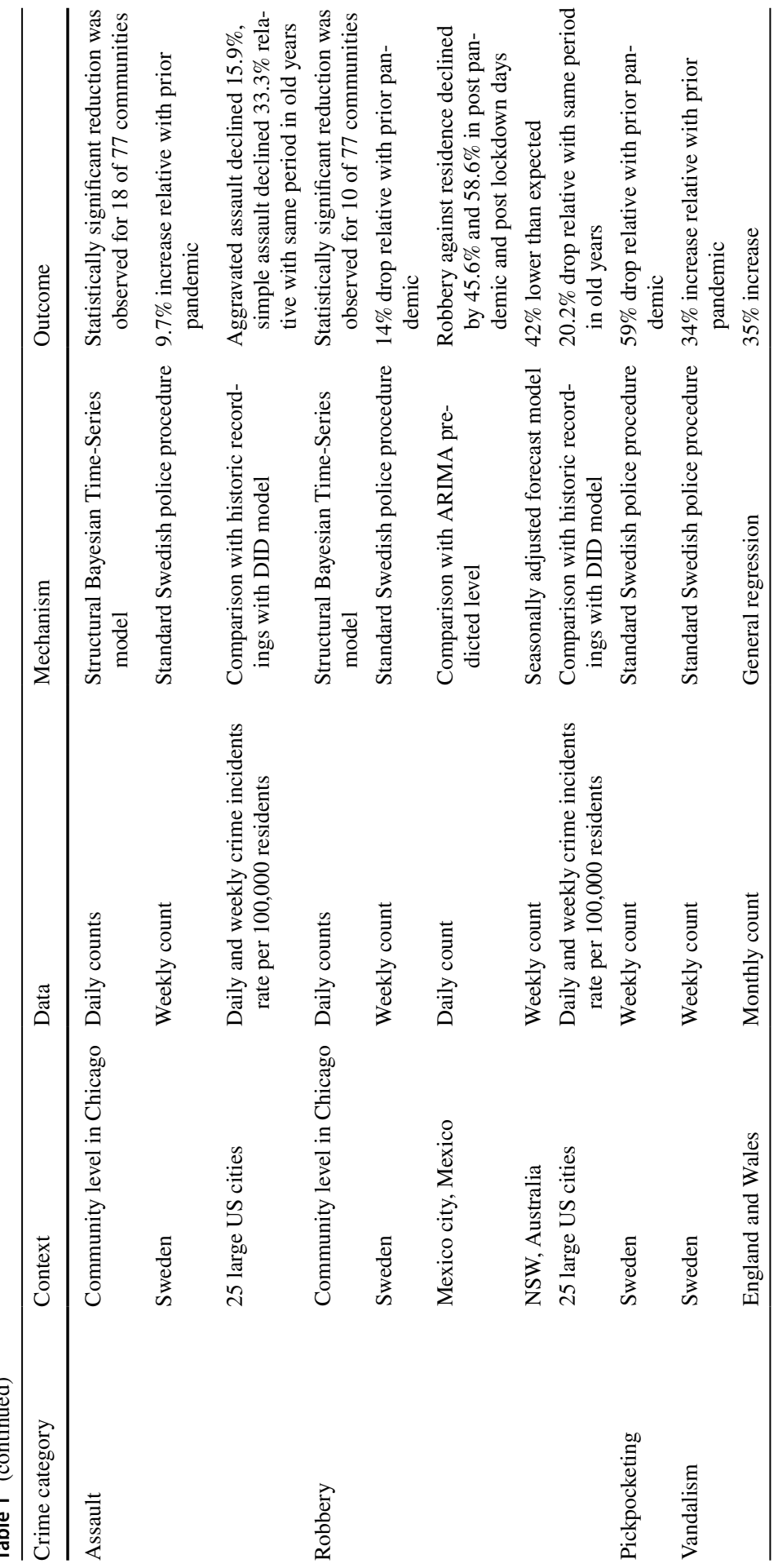




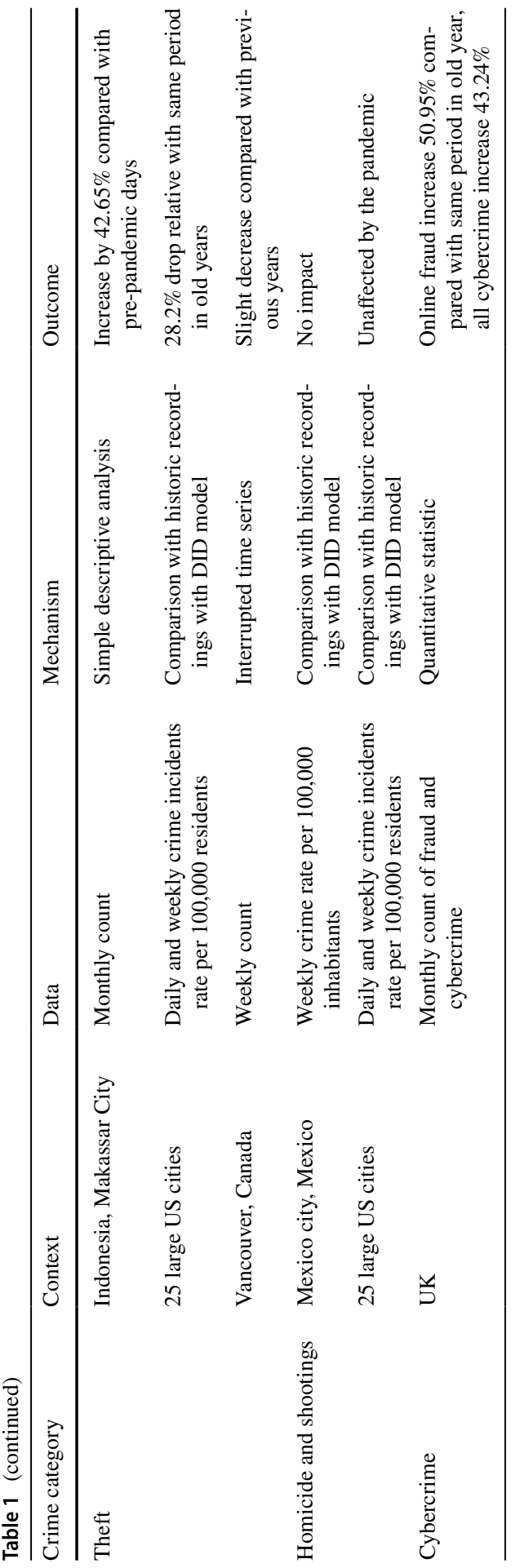


and place. Among the available studies, findings show that many crimes including property offenses, vandalism, violence, and cyber victimizations occurring in the USA, UK, Australia, Canada, and Sweden were indeed significantly impacted when compared with the historic or the expected crime levels (Ashby, 2020; Boman \& Gallupe, 2020; Buchanan et al., 2020; Felson et al., 2020; Gerell et al., 2020; Halford et al., 2020; Hodgkinson \& Andresen, 2020; Jennings \& Perez, 2020; Langton et al., 2021; Mohler et al., 2020; Payne et al., 2021; Piquero et al., 2020).

As inferred from the table, property crime, the one crime type believed to be greatly impacted by pandemic-related policies, demonstrates significant reductions compared with pre-pandemic periods. As indicated by routine activity theory, lockdown, stay-at-home, and social distancing strategies serve to limit the public activities and so the opportunity of potential offenders interacting with victims or targets are significantly curtailed, which results in less property crime during the pandemic lockdown period. For example, residential burglary and robbery was observed to significantly decline in the USA (Mohler et al., 2020), Sweden (Gerell et al., 2020), Mexico (Estévez, 2021), New Zealand (Cheung and Gunby, 2021), and Australia (Kim \& Leung, 2020), while for vehicle theft, more reductions were observed for the USA (Campedelli et al., 2020), Mexico (Miyar et al., 2021), and Australia (Kim \& Leung, 2020; Payne \& Morgan, 2020) except Canada (Hodgkinson \& Andresen, 2020) from which the crime slightly decreased. Pickpocketing, though was only reported in a few countries, but a moderate high reduction, was reported in Sweden (Gerell et al., 2020). The one exception to this pattern of results was the increase in theft during the pandemic in Makassar, Indonesia (Syamsuddin et al., 2021). Similar to property crimes, some types of violence and assault also experienced a decline in the USA (Ashby, 2020; Boman \& Gallupe, 2020; Bullinger et al., 2020), Sweden (Gerell et al., 2020), Mexico (Estévez, 2021; Miyar et al., 2021), and Australia (Kim \& Leung, 2020; Payne et al., 2021). An increase in vandalism was, however, observed in the USA (Mohler et al., 2020), Sweden (Gerell et al., 2020), and England and Wales (Kirchmaier \& Villa, 2020), which shows that anti-social behaviors were more likely to increase during restrictions. Drug crimes, however, varied across different countries. It has been found that drug-related crime dropped in the USA (Abrams, 2021), but increases were observed in Sweden (Gerell et al., 2020), Australia (Kim \& Leung, 2020), and England and Wales (Kirchmaier \& Villa, 2020). ${ }^{1}$

In addition to these trends, researchers have also investigated the potential variability of changes in crime across space. For example, Campedelli et al. (2020) investigated how pandemic-related interventions affected criminal activity at the community level in Chicago and found that there was significant crime variation across communities and crime types. Among the 77 investigated communities, only $10(13 \%)$ experienced a statistically significant reduction in burglary and robbery during the post-intervention follow-up period, while 18 communities (23\%) experienced a significant reduction in assault, and 35 communities $(46 \%)$ experienced a statistical reduction in drug offenses. These results suggest that the decline of

\footnotetext{
1 Although our focus in this paper lies with property crime, it is worth noting that both homicides (Rosenfeld and Lopez, 2020) and domestic violence (Piquero et al., 2021) have been found to increase since the onset of the pandemic and during lockdown periods, respectively.
} 
crime that started with the pandemic was not homogeneously distributed in space. In attempting to interpret the various crime reductions in heterogenous community environments, these authors found that the number of inhabitants was the only factor positively associated with all crime types, which indicated that more people staying at home likely increase capable guardianship and served to lower the opportunities for crime. Similar effects were reported by Syamsuddin et al. (2021), in which theft was found to be higher in malls, restaurants, and shops because the places were unguarded. Using block group data from Detroit, Felson et al. (2020) examined burglary during the transition days of routine activity change and found that burglaries kept increasing in the block groups with mixed land use rather than the ones being dominated by residential land use.

Besides the physical space, cybercrime, an offense occurring in virtual space was also observed to change. Using monthly data on fraud and cybercrime known to the police in the UK, Buil et al. (2021) analyzed the changes in crime from pre to during the pandemic days. As indicated in Table 1, online cybercrime increased by $43 \%$, with online fraud (online shopping) increasing by $51 \%$ compared with historic trends. This suggests that the lockdown orders led to more people spending more time in online entertaining, shopping, ${ }^{2}$ conferencing and served to enhance the offending opportunity described by routine activity theory on the internet.

Undoubtedly, these studies have served as an important foundation to what criminologists have been able to document with respect to crime in the COVID-19 era. Yet, there are some limitations to this body of work and some unique opportunities for extension that await the field. The first surrounds the measurement standard, i.e., daily, weekly, or monthly counts of crime was used as the major index to measure changes in crime by type, time, and space (Campedelli et al., 2020; Gerell et al., 2020; Kim \& Leung, 2020; Syamsuddin et al., 2021), but the assumption that population size remained constant during the pandemic was not always stable. That is, lockdowns and stay-at-home orders are most relevant to individuals who permanently reside in the city, but for non-inhabitants like travellers, flow-in workers, and commuters, they would leave the city and lower the total population level during the pandemic period, such that the crime risk would be distributed on fewer people. Hence, an alternative solution to avoiding an over-estimated crime risk is to use a more dynamic crime rate rather than crime count to precisely compute crime levels.

Another limitation to the current work is the sampling frequency of crime. Some of the studies that have been conducted have taken advantage of weekly or monthly time series data for estimating the effect, if any, of the COVID-19 pandemic and associated restrictions thus smoothing the periodicity often found in crime data when analyzed at the daily level (e.g., Ashby, 2020; Hodgkinson \& Andresen, 2020). ${ }^{3}$ Of course, researchers are often limited by the data that is made available to them, but one of the disadvantages of using less granular daily data is that it makes it more difficult to account for the drastic nature of a change to a system (Borrion et al., 2020). For

\footnotetext{
${ }^{2}$ Retail Sales, Great Britain: May 2020, Office for National Statistics. Available from: https://www.ons. gov.uk/businessindustryandtrade/retailindustry/bulletins/retailsales/latest\#stores-sellingonline.

${ }^{3}$ We recognize, of course, that some decisions to model crime data in weekly or monthly units may have more to do with the sample size, i.e., few daily cases.
} 
example, lockdown measures that were put in place occurred on a single day and in many cases persisted for several weeks or months. In the event that both the start and end of the lockdown occurred in a temporally discrete manner, for example, a Wednesday, then the true nature of the changes would be, at least partly, "washed out."

The other limitation surrounds the methodology. A number of studies, including some of our own, have taken advantage of time series forecasting methods, namely intervention analyses that utilize Autoregressive Integrated Moving Average (ARIMA) models or other statistical, Bayesian, or machine learning forecasting techniques, to generate a predicted or expected crime levels. These studies have endeavored to generate a counterfactual of the expected mean count of crime events had the pandemic not occurred (e.g., Ashby, 2020; Borrion et al., 2020; Campedelli et al., 2020; Halford et al., 2020; Hodgkinson \& Andresen, 2020; Kurland et al., 2021; Piquero et al., 2020). All of these studies have endeavored to control for stationarity (an assumption required for time-series forecasting) in the respective series of interest because crime by its nature tends to be non-stationary. Indeed, relationships between crime and meteorological conditions as well as the routine activity of a society have been repeatedly found in the extant literature and ultimately shape the opportunity structure for crime to occur. For example, holidays, extreme weather conditions, and exceptional events have all been shown to influence crime patterns (e.g., Chen et al., 2011; Cohn \& Rotton, 2003; Decker et al., 2007; Kurland \& Johnson, 2021; Kurland et al., 2014), and not taking account of these in one's model may lead to less reliable forecasts. ${ }^{4}$

\section{The case of China}

The fight against the COVID-19 pandemic is still ongoing and more work aiming to test pandemic restrictions on crime continues to emerge. Many of the studies that have been conducted hitherto did so for cities, counties, or regions that continued to have some form of restrictions in place. This makes quantifying the magnitude of the effect on crime stemming from the pandemic and the multitude of measures put in place by governments to curb the spread difficult, and also means that the full effect of what may have transpired may not have been fully captured by the associated models. One of the few places on earth that have not only experienced the pandemic, but also associated restrictions, and reopened with a return to normal routines is China, making it a particularly interesting region for criminological studies that seek to tease apart the effect of COVID-19 and the lockdown in particular on the pattern of crime that emerged.

\footnotetext{
${ }^{4}$ We noted that some of our own prior work is also limited in this regard. However, we obviously recognize the "ask" made here as many of these data, including weather conditions, are simply unavailable or difficult to combine with crime data. We simply are pointing this out as another potential influence on crime changes during pandemic lockdowns, especially since these weather-related events occur in different ways throughout the world given how winters/summers operate around the globe.
} 
China was the first nation to discover and officially report a COVID-19 case and also the first to implement lockdown and stay-at-home strategy to control the spread of the virus. As early as January 23rd 2020, three provinces of China (Zhejiang, Hunan, and Guangdong) started the First Level Public Health Emergency Response ${ }^{5}$ and pandemic lockdown order, ${ }^{6}$ and in the following week, the other 28 provinces of China began the strategy. After combating the virus for several months, all 31 provinces announced that the COVID-19 virus had been successfully controlled, and consequently, the Emergency Response level and lockdown orders in every province were lifted. ${ }^{7}$ Today, despite the persistence of reports in some cities and towns across China, there is a general consensus that the risk of the virus spreading across the country has ceased (although reports of the Delta variant emerging in the country may negate this statement). Given these factors, and the gradual return to normalcy that has taken place across China, a case study that tests the patterns of crime from routine activity theoretical perspective during the initial onslaught of the virus and mitigation efforts put into place is therefore not only possible, but also highly valuable.

In China, the measures aimed at reducing the spread of the virus included:

- All public transport (including subway lines, shuttle bus, and taxi) stopped.

- All business, entertainments, sport activities, production, and schools were closed.

- People were all required to stay at home until the lockdown was over.

- Only the necessary life suppliers (e.g., supermarket, food shops, restaurants) remained open but little customers were present at the places.

- Food, water, vegetables, fruits, etc. were delivered directly to people's accommodations by neighborhood staff, police, and community volunteers.

Following the introduction of the above policies, public spaces were empty, crowds had disappeared, and regular properties, for example, empty residential houses, automobiles, motorcycles, bicycles, become more available than before. Meanwhile, offenders were less likely to be outside due to strict stay-at-home orders. On the other hand, as people spent more time at home, much of their business activities switched from offline to online, and they also spent more time shopping online, using e-commerce, engaging in entertainment, etc. which exposed them to cybercrime (Buil et al., 2021). In this paper, we assess the following hypotheses:

\footnotetext{
${ }^{5}$ According to the nature, severity, and scope of impact, public health emergencies in China are classified into four levels (I, II, III, and IV), with severity decreasing from level I to level IV. In level I, the transportation, civil aviation, railway, and other public departments were urged to formulate emergency response plans.

${ }^{6}$ The pandemic lockdown refers to the strict policy meant to prevent the COVID-19 virus from spreading. During the lockdown days, all public transport, including buses, railways, flights, and ferry services, were suspended, the airport, railway station, and metro lines were all closed, and all residents were also not allowed to leave the city without permission from the authorities.

${ }^{7}$ The lockdown order was implemented instantly when the first level of emergency response was started up; thus, the sign of lockdown lifting is defined as the emergency response being adjusted from level I to level II.
} 
H1 Traditional property crime incidence would experience significant reductions during the pandemic because stay-at-home orders reduced many opportunities for crimes such as burglary and theft.

H2 Cybercrime, specifically online fraud, would not decrease as much as property crimes and even increase during the pandemic period as people spend more time using the internet to conduct activities related to business, school, e-commerce, and entertainment.

\section{Data and methods}

The data utilized for this study are the daily counts of calls for police service that were reported to the local Police Bureau and kept in the Computer Aid Dispatch system (CAD) from an anonymous medium-sized city ${ }^{8}$ (M1-city hereafter) located in south China. Although the calls to police data is a subset of all recorded crimes in the city, it does provide a good measure of crime during the pandemic period, one that has been used in other COVID-19/crime-related studies (Bullinger et al., 2020; Dai et al., 2021). The data includes eight typical property offenses: automobile theft, electromobile (also referred to as electric scooters) theft, motorcycle theft, bicycle theft, theft from automobiles, residential burglary, cyber-fraud, and pickpocketing. ${ }^{9}$ Given the offense types included in the analysis, and the conditions required to carry out these different crimes, the pandemic provides a more direct opportunity to assess the utility of routine activity theory (Hawdon et al., 2020; Machimbarrena et al., 2018). The data are for the period between 1 March 2017 and 31 March 2020. According to an official report, the First Level Public Health Emergency Response to COVID-19 and the lockdown strategy in the city commenced on 24 January 2020 and was lifted on 31 March 2020 by the local municipal government, providing a lockdown period that lasted a total 68 days. Figure 1 provides the standardized cumulative distribution of COVID-19 cases that occurred in M1-city across both the lockdown period and the period immediately after the restriction was lifted. Considerable growth in COVID-19 cases occurred in M1-city during the first roughly 30 days, but this leveled off with relatively limited additional growth resulting in the flattening of the curve thereafter. Indeed, not a single additional case was found during the entire month of March and so it was determined that the spread of the virus had been successfully stopped leading to a lifting of the lockdown order on 31 March 2020.

Much of the research on COVID and crime published thus far has utilized raw crime counts with several also attempting to control for the underlying population at risk (see e.g., Mohler et al., 2020; Campedelli et al., 2020). Herein we make use

\footnotetext{
${ }^{8}$ The city has a population of around 11 million, is roughly $8000 \mathrm{~km}^{2}$, and is largely urbanized. Prior to the pandemic, the city had some of the country's lowest unemployment rates of around $3 \%$ and among the China's top ranked GDPs.

9 The crime types were assigned to the call for police service manually in two steps. Firstly, the operator will assign an initial crime type to the call according to the victim's oral or text description, and then the crime type would be confirmed or corrected after officers' on-site investigation.
} 


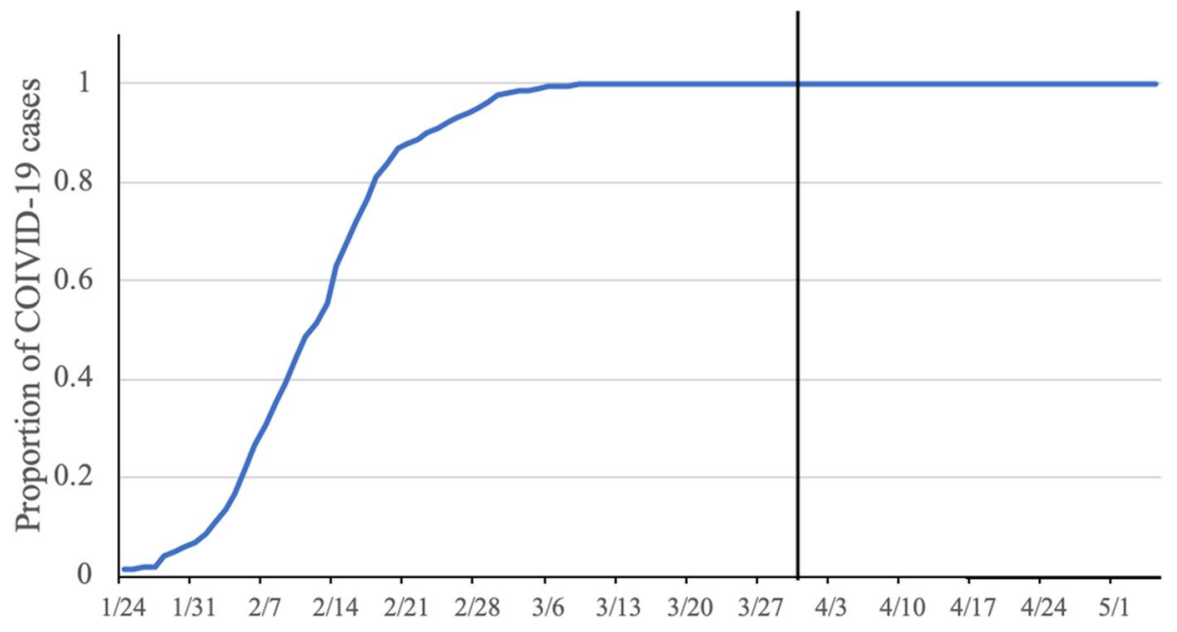

Fig. 1 Standardized cumulative distribution of confirmed COVID-19 cases over time in M1-city, China. The black line is the day when lockdown order was lifted by the government. The data was accessed via: https://github.com/BlankerL/DXY-COVID-19-Data (accessed 1 May 2021)

of the raw counts of these crime types of interest, but also consider the underlying population. More specifically, given the intersection of the start of the COVID-19 pandemic and the Chinese Spring Festival (24th to 31st January 2020), we needed to try and account for this known change in the availability of potential offenders and targets. Approximately one-third of the population of M1-city departed at the onset of the Chinese Spring Festival. They left the city and returned to their home cities/ towns prior to the lockdown commencing, and also not returning to M1-city until after the lockdown order was lifted (on 31 March 2020), that is 60 days after the end of the festival. ${ }^{10}$ Given the above, we attempt to control for this by generating daily offense rates for the period before and during the COVID-19 lockdown by calculating an offense rate per 100,000 population by day.

A regression discontinuity in time (RDiT) design, also sometimes referred to as an interrupted time series analysis with segmented regression, is employed to analyze the potential impact of the COVID-19 pandemic lockdown on crime in M1-city. However, prior to the RDiT, a stepwise multi-stage de-seasonalization process has to be undertaken to better isolate the overall change that can be confidently attributed to the lockdown treatment. The entire time series $\left\{y_{1}, \ldots, y_{N}\right\}$, is partitioned into two segments, the pre-lockdown period given by $\left\{y_{1}, \ldots, y_{N}\right\}$ and the lockdown period

\footnotetext{
${ }^{10}$ Traditionally, the floating population would return to their home cities/towns during the Spring Festival days. As the outbreak time was coinciding with the Spring Festival in 2020, we assumed M1-city's entire floating population left before January 23rd and did not return until the lockdown order was lifted. To more accurately capture the city's population, the rates were calculated using the total population for the non-lockdown periods (11 million population according to the city's Annual Statistic Yearbook in 2019). While the reduced population count, 8 million, was utilized for the lockdown period rate calculation (approximately 3 million people belonged to the floating population according to the Statistic Yearbook in 2019 , roughly one-third of the whole population in the city).
} 

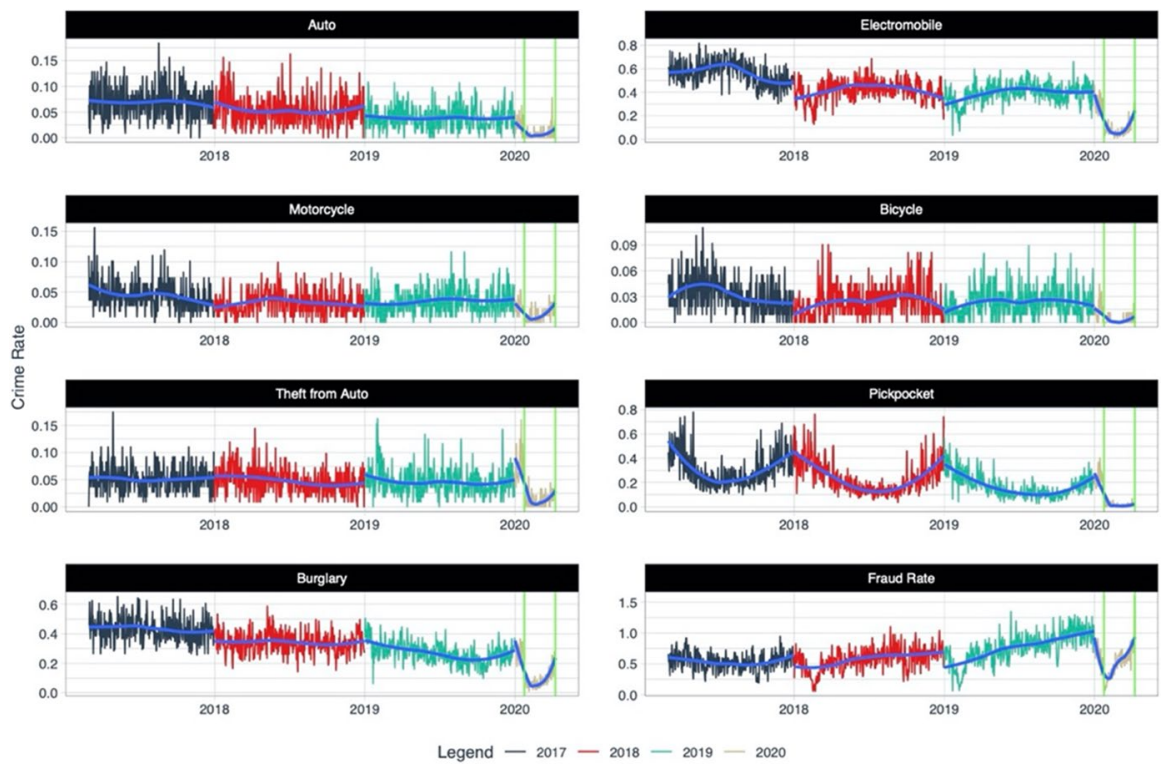

Fig. 2 The observed series of auto theft, electromobile theft, motorcycle theft, bicycle theft, theft from auto, pickpocketing, residential burglary, and cyber-fraud calls for service rates from 1 March 2017 to 31 March 2020 by year with a Loess smoother (blue) to help visualize the overall yearly trend of the rates (per 100,000 persons), and green vertical lines demarcating the full temporal extent of the lockdown period in M1-city

given by $\left\{y_{M+1}, \ldots, y_{N}\right\}$, with $N=1127^{11}$ and $M=68$. Figure 2 provides a visualization of each of the respective categories of crime of interest in this study with a Loess smoother (blue) applied at a yearly-bin as well two vertical green lines that demarcate the first and final day of the lockdown period, $\left\{y_{M+1}, \ldots, y_{N}\right\}$, and the lockdown segment.

Each respective segment is decomposed using Seasonal-Trend-Loess (additive) decomposition, as per Eq. 1:

$$
y_{t}^{i}=S_{t}^{i}+T_{t}^{i}+R_{t}^{i}
$$

where $y_{t}^{i}$ is the number of daily cases (or rate) for call for service type $i$ on day $t, S_{t}^{i}$ is the season component, $T_{t}^{i}$ is the trend component, and $R_{t}^{i}$ is the remainder component, all for call for service type $i$ at day $t$.

A four-stage stepwise approach is taken herein to illustrate how trend, seasonality, and other covariates that are major contributors to the total variance in each series (pre- and lockdown), but are criminologically (at least herein) unimportant, are removed to ensure they do not obscure the potential lockdown effect, that is of

11 The time length of historic days before lockdown period (1 March 2017 through 23 January 2020). 
greater significance (Granger, 1978; Lovell, 1963; Zellner, 1978). First, the trend component is estimated as per Eq. 2:

$$
y_{t}^{i}=\beta_{0}^{i}+\beta_{1} T_{t}^{i}+u_{t}^{i}
$$

where $u_{t}^{i}$ is white noise.

Next, a series of harmonic terms are identified to account for seasonality that occurs faster than the primary seasonality of the series is estimated as per Eq. 3:

$$
y_{t}^{i}=\beta_{0}^{i}+\beta_{1} T_{t}^{i}+\sum_{<k>} \beta_{2, k}^{i} \cos \left(2 \pi \omega_{k}^{i} t\right)+\beta_{3, k}^{i} \sin \left(2 \pi \omega_{k}^{i} t\right)+u_{t}^{i}
$$

where the set of $K$ harmonics, $\cos \left(2 \pi \omega_{k}{ }^{i} t\right)$ and $\sin \left(2 \pi \omega_{k}{ }^{i} t\right)$, is determined for each segment using the small sample corrected Akaike Information Criterion (AICc), ${ }^{12}$ and where $\omega_{k}^{i}$ is a multiple of $1 / 365.25$ for daily data.

The third step included the addition of fixed effects meant to control for the various cyclicities that occur over different periods of time that were not fully captured using harmonics as per Eq. 4:

$$
y_{t}^{i}=\beta_{0}^{i}+\beta_{1} T_{t}^{i}+\sum_{<k>} \beta_{2, k}^{i} \cos \left(2 \pi \omega_{k}^{i} t\right)+\beta_{3, k}^{i} \sin \left(2 \pi \omega_{k}^{i} t\right)+\beta_{4} D W_{t}^{i}+\beta_{5} W M_{t}^{i}+\beta_{6} M_{t}^{i}+\beta_{7} Y_{t}^{i}+u_{t}^{i}
$$

where $D W_{t}^{i}, W M_{t}^{i}, M_{t}^{i}$, and $Y_{t}^{i}$ are fixed-effect indicator variables for the day of the week, week of the month, month, and year ${ }^{13}$ respectively for call for service type $i$ at day $t$.

The penultimate step in the de-seasonalization process incorporates numerous time-varying covariates that have been shown to have a relationship to crime patterns in the extant criminological literature. This is done as per Eq. 5:

$$
\begin{array}{r}
y_{t}^{i}=\beta_{0}^{i}+\beta_{1} T_{t}^{i}+\sum_{<k>} \beta_{2, k}^{i} \cos \left(2 \pi \omega_{k}^{i} t\right)+\beta_{3, k}^{i} \sin \left(2 \pi \omega_{k}^{i} t\right)+ \\
\beta_{4} D W_{t}^{i}+\beta_{5} W M_{t}^{i}+\beta_{6} M_{t}^{i}+\beta_{7} Y_{t}^{i}+ \\
\beta_{8} H_{t}^{i}+\beta_{9} P_{t}^{i}+\beta_{10} W_{t}^{i}+\beta_{11} T M P_{t}^{i}+\beta_{12} A Q_{t}^{i}+u_{t}^{i}
\end{array}
$$

where $H_{t}^{i}$ is a time-varying covariate for holidays where 1 if a holiday, 0 otherwise, while $P_{t}^{i}, W_{t}^{i}, T M P_{t}^{i}$, and $A Q_{t}^{i}$ are time-varying covariates for precipitation, wind, temperature, and air quality for call for service type $i$ at day $t$.

To help readers visualize the approach to de-seasonalizing the data, we have taken the fitted values from each of the eight models (Fig. 3), four for the prelockdown period given by $\left\{\hat{y}_{1}, \ldots, \hat{y}_{M}\right\}$ and four for the lockdown period given by $\left\{\hat{y}_{M+1}, \ldots, \hat{y}_{N}\right\}$, and joined them to have the fitted values for the entire series, $\left\{\hat{y}_{1}, \ldots, \hat{y}_{N}\right\}$ as a single segment. As an example of our approach, each facet of Fig. 3 shows how the fitted (red) improves relative to the observed (black), starting from the first simple trend model to the fourth most complex model that

\footnotetext{
12 Fourier order did vary by the segment being modeled and was optimized through the identification of the order that minimized AICc (De Livera et al., 2011).

13 This term was not included for the lockdown period as the entirety of this segment occurred in 2020.
} 

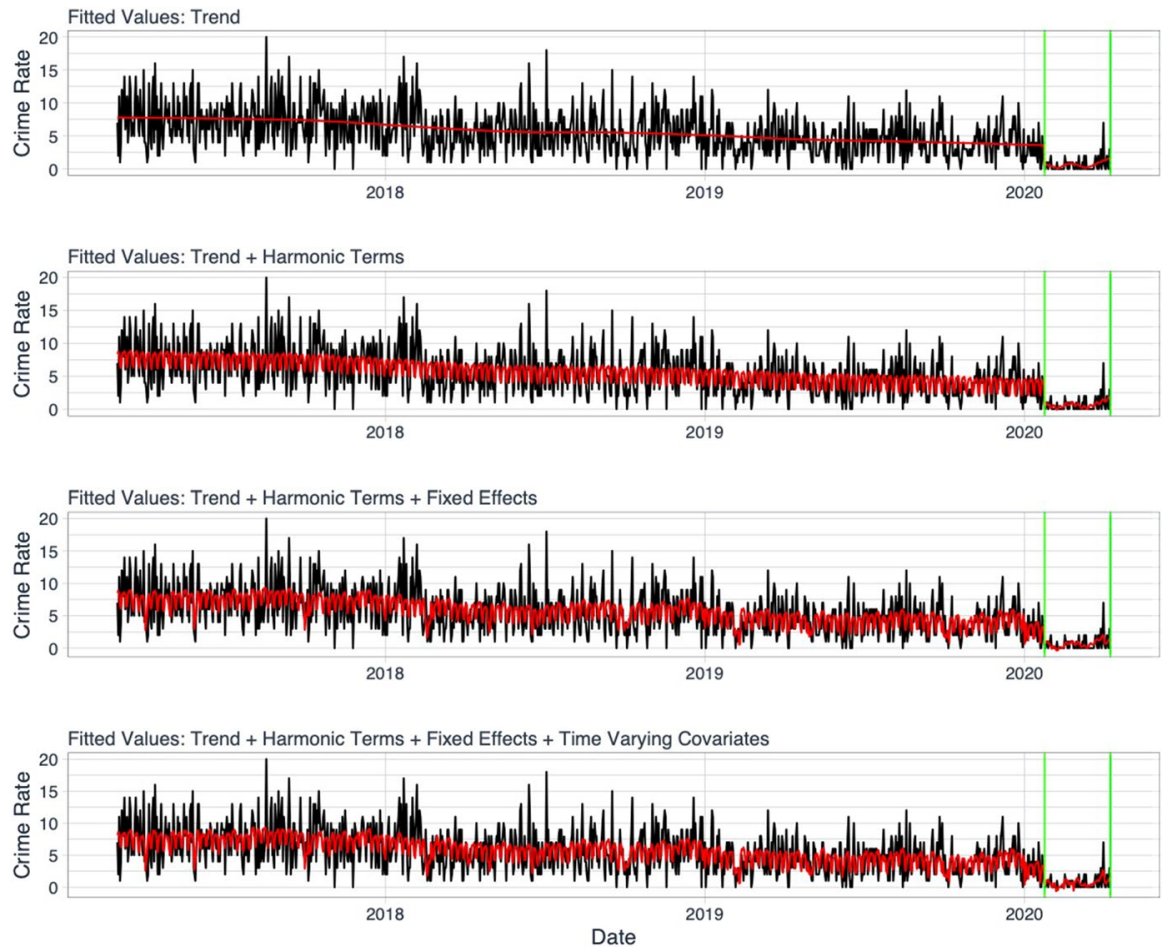

Fig. 3 The observed series for cyber-fraud calls for service rates from 1 March 2017 to 31 March 2020 (black) with the fitted values (red) for each of the stepwise models for the full temporal extent of the lockdown period in M1-city

included a trend term, harmonics components, fixed effects, and time-varying covariates thus capturing more of the variance that might be explained by factors other than the lockdown. Such an approach is critical to isolating any time-based intervention/treatment effect for a regression discontinuity study design or interrupted time series design.

The seasonal component of the model is calculated by subtracting the trend and residuals from our final pre- and lockdown models (Eq. 5) as per Eq. 6:

$$
S_{t}^{i}=y_{t}^{i}-T_{t}^{i}-u_{t}
$$

where $S_{t}^{i}$ is the seasonal for call for service type $i$ at day $t$.

De-seasoning was completed by subtracting the seasonal component, $S_{t}^{i}$, from the observed series, $y_{t}{ }^{i}$.

$$
D S_{t}^{i}=y_{t}^{i}-S_{t}^{i}
$$

where $D S_{t}^{i}$ is the de-seasoned series. A new time series, $C_{t}^{i}$, is then created by joining the values from the final de-seasonalized models for the pre- and lockdown periods. A simple RDiT model is then used to test (1) whether a difference exists 
between pre- and lockdown periods, and, if so, (2) how large and in what direction, and (3) what this amounts to across the entirety of the lockdown period as per Eq. 8:

$$
C_{t}^{i}=\gamma_{0}^{i}+\gamma_{1} \text { time }_{t}^{i}+\gamma_{2} \operatorname{lockdown}_{t}^{i}+\gamma_{3} \text { timeafterlockdown }_{t}^{i}+e_{t}^{i}
$$

where $C_{t}^{i}$ is the observed crime trend value in day $t,(1, \ldots, 1127)$, for $i$ th crime type, time $_{t}^{i}(1, \ldots, 1127)$ is a continuous variable indicating time in days at day $t$ from the start of the observation period, $\operatorname{lockdown}_{t}{ }^{i}$ is an indicator for day $t$ occurring before (lockdown $=0$ ) or after (intervention $=1$ ), timeafterlockdown ${ }_{t}^{i}$ is a continuous variable counting the number of days after the lockdown began on day $t$, coded 0 before the lockdown and $(1, \ldots, 68)$ after the lockdown, and $e_{t}$ is random error.

The same method is used across all eight crime types for the crime counts and rates (per 100,000 population) for the period between 1 March 2017 and 31 March 2020 to estimate the immediate effect of the lockdown on the count (or rate) of the different categories. However, it is possible to further compare estimates for the time after lockdown values of the lockdown outcome to values estimated at that time but based on baseline level and trend only, as if the lockdown (counterfactual value) had not occurred. We can express the lockdown effect as the absolute difference between the predicted outcome based on the intervention and the counterfactual value. To estimate the lockdown effect in M1-city, we express the expected results from the RDiT Eq. (6) at day 1127 (23 January 2020), which is 68 (31 March 2020) days after the lockdown was implemented as per Eq. 7:

$$
\widehat{C}_{1127(\text { with lockdown) }}^{i}=\hat{\gamma}_{0}^{i}+1127 \hat{\gamma}_{1}^{i}+\hat{\gamma}_{2}^{i}+68 \hat{\gamma}_{3}^{i}
$$

Next, we considered RDiT Eq. (6) at 1127 days, had the lockdown policy not been implemented. Put differently, without any lockdown effects in the model as per Eq. 8:

$$
\widehat{C}_{1127(\text { without lockdown) }}^{i}=\widehat{\gamma}_{0}^{i}+1127 \widehat{\gamma}_{1}^{i}
$$

The difference between Eqs. 7 and 8, $\hat{C}_{1127 \text { (lockdown) }}^{i}-\hat{C}_{1127 \text { (no lockdown) }}^{i}=\hat{\gamma}_{2}^{i}+68 \hat{\gamma}_{3}^{i}$, is the estimate of the absolute lockdown effect or the total difference in the number (or rate) of calls for service for each respective category of crime for the entirety of the lockdown period.

\section{Results}

The results from the RDiT suggest an immediate, drastic impact of the lockdown on the counts and rates for all eight crime categories for M1-city. Figure 4 provides a clear illustration of the difference between the period before and after the lockdown and the fitted values and trends for each of the series.

There was an immediate reduction in daily auto theft of $\sim 3(-3.09,95 \% \mathrm{CI}$ : $[-4.38,-1.81])$. Similarly sized decreases were found in daily motorcycle $(-3.15$, 95\% CI: [-4.18,-2.13]), bicycle $(-1.98$, 95\% CI: [-2.84,-1.12]), and theft 

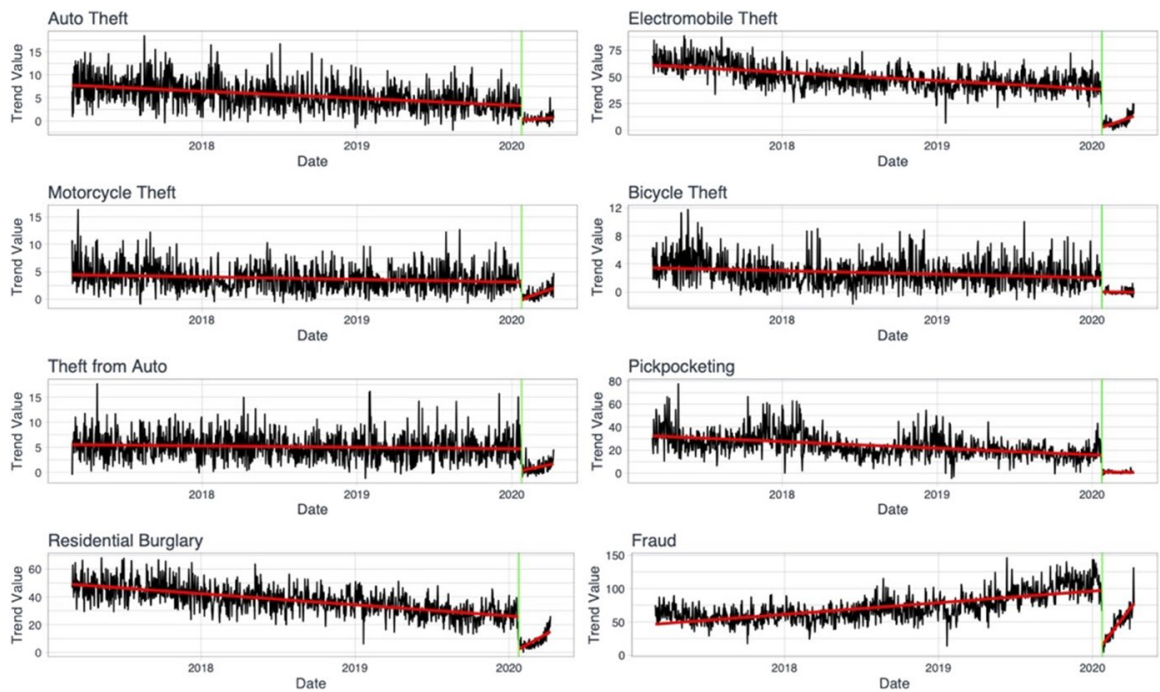

Fig. 4 Regression discontinuity in time (RDiT) results for each of the trends (black) for the eight categories of crime from 1 March 2017 to 31 March 2020 with associated linear fit (red) for the period prior to the lockdown and the lockdown for M1-city after controlling for trend, seasonality, and numerous timevarying covariates

from auto $(-4.33,95 \% \mathrm{CI}:[-5.54,-3.16])$ calls for service events. More sizeable reductions were found in the daily count of pickpocketing $(-14.49,95 \% \mathrm{CI}$ : $[-18.72,-10.26])$, residential burglary $(-23.71,95 \% \mathrm{CI}:[-27.18,-20.23)]$, and electromobile theft $(-35.61,95 \%$ CI: $[-39.83,-31.37])$. The largest overall daily reduction of call for service counts was for the cyber-fraud category $(-82.62,95 \%$ CI: $[-89.73,-75.52])$. Of importance to note here is that cyber-fraud was the only category of crime prior to the lockdown to have a positive trend and was the most prevalent form of daily crime examined for M1-city. This combination of factors makes the drop in cyber-fraud, in Fig. 4, quite large. Notably, the trend for cyberfraud during the lockdown period is also steep and positive, nearly approaching prelockdown levels by the end of the period suggesting a kind of criminogenic resiliency not seen in the other crime categories included in the study and in the majority of the research conducted on COVID-19 lockdowns and criminal activity.

The main advantage of the RDiT approach to other similar techniques is the ability to estimate the counterfactual period as opposed to providing a simple estimate of a change in the mean count (or rate). Here the results of the RDiT illuminate just how profound the effect of the lockdown really was on changes in the crime patterns for M1-city. When taken together, the reduction among these categories of crime results in 9939 fewer calls for police service during the lockdown than what would have been expected had the lockdown not occurred. Bicycle theft $(-148.66$ (95\% CI: [-269.18,-28.14]), motorcycle theft $(-157.55,95 \%$ CI: $[-301.06,-14.03])$, auto theft $(-205.88,95 \%$ CI: $[-386.05,-25.71])$, and theft from auto (-276.69, 95\% CI: [-443.48, - 109.90]) all experienced a hundred to several hundred fewer calls, while pickpocketing $(-1068.56,95 \% \mathrm{CI}$ : [-1660.01, -477.11$])$, residential burglary $(-1240.09,95 \%$ CI: $-1726.36,-753.82])$, electromobile theft $(-2833.04,95 \%$ CI: 

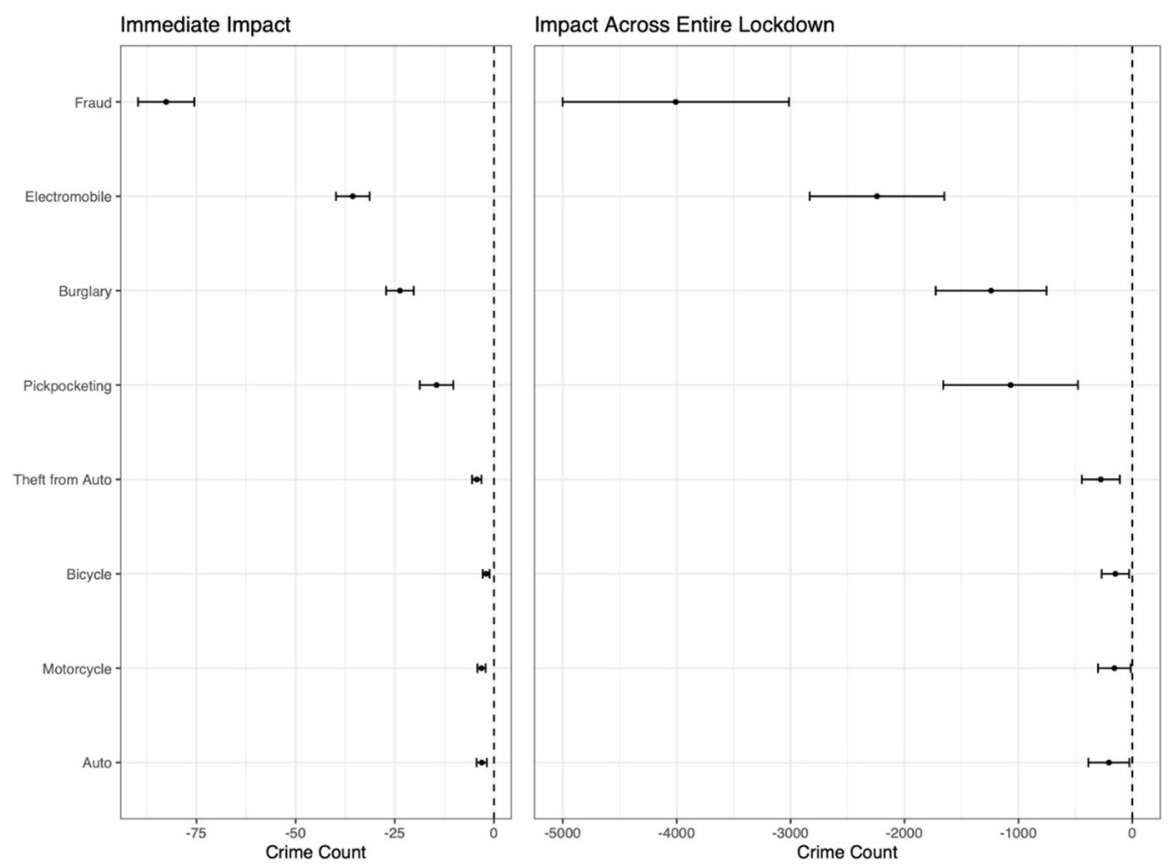

Fig. 5 Regression discontinuity in time (RDiT) coefficients and associated 95\% CIs for the immediate impact (left panel) and the impact across the entire lockdown period (right panel) for each of the eight categories of crime

[-2833.04,-1650.09]), and cyber-fraud (-4007.44, 95\% CI: [-5000.91,-3013.97]) experienced thousands of fewer calls for service. Figure 5 provides a visualization of the magnitude of both the immediate impact identified using the RDiT model, as well as the impact of the lockdown for the entire lockdown period.

The same analysis applied to crime rates, that is taking into account the approximately $30 \%$ drop in population during the lockdown, yields very similar results. Significant reduction in crime rates was found for almost all studied crime categories, both immediately and across the lockdown period. The one exception is motorcycle theft, which was not statistically significant in the longer term: $-1.23(95 \%$ CI: [-2.54, 0.07]). The greatest change concerns cyber-fraud, with an immediate reduction in rates of -0.7 (95\% CI: [-0.7662, - 0.63683]) and -27.7 (95\% CI: $[-36.75,-18.75])$ over the entire lockdown period. Comparison between other crime types shows the immediate and longer-term effects follow a similar order as that found with crime counts: theft of electromobiles $(-0.3 ;-18.3)$ followed by burglary $(-0.2 ;-9.47)$ and pickpocketing $(-0.12 ;-1.31)$. Other categories showed the least decline, with a smaller reduction in crime rates: theft from automobiles $(-0.03 ;-2.29)$, automobile theft $(-0.02 ;-1.74)$, motorcycles $(-0.02 ;-1.23)$. Theft of bicycles $(-0.01 ;-1.31)$ comes last (Figs. 6 and 7). 

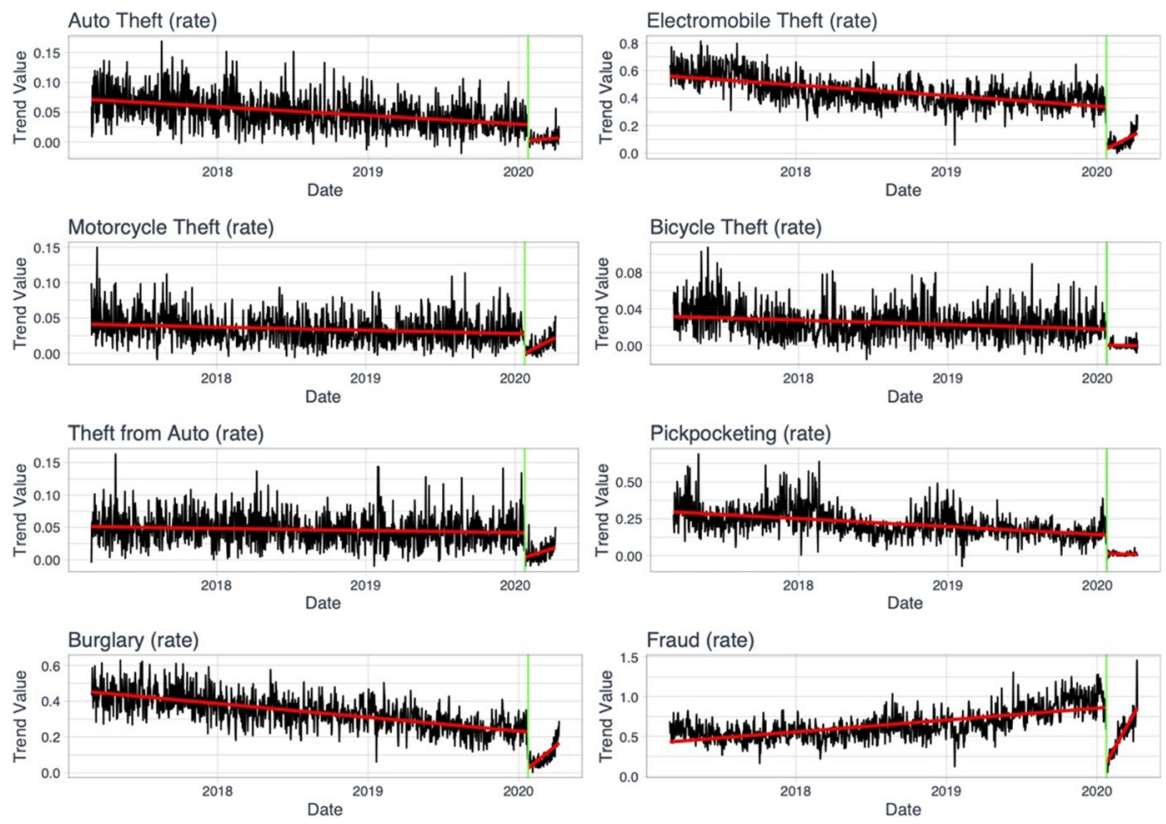

Fig. 6 Regression discontinuity in time (RDiT) results for each of the rate trends (black) for the eight categories of crime from 1 March 2017 to 31 March 2020 with associated linear fit (red) for the period prior to the lockdown and the lockdown for M1-city after controlling for trend, seasonality, and numerous time-varying covariates

\section{Discussion}

China was the first country to experience the novel coronavirus and the public health and safety consequences of COVID-19 and its related policies initiated to thwart its spread have been studied around the world. A great majority of those studies have examined the effect of pandemic lockdown strategies on changes in criminal activity, as there are reasons to suspect that some crimes would increase, such as aggravated assault and domestic violence-the reality which has been borne out (see e.g., Rosenfeld \& Lopez, 2020; Piquero et al., 2021), while other types of crime, such as acquisitive property-oriented offenses, would be expected to decrease because of changes in routine activities thwarted many crime opportunities from occurring.

This article investigated the impact of the lockdown strategy in responding to COVID-19 on crime levels before and during the lockdown period in a middle-sized Chinese city. By introducing the strict lockdown strategies aiming to control the virus spreading, it is believed that pandemic-related policies seriously disrupted people's routine activities there, and so the crimes are expected to be significantly influenced (Borrion et al., 2020). Two theoretical assumptions following the principles of routine activity theory were proposed to assess 

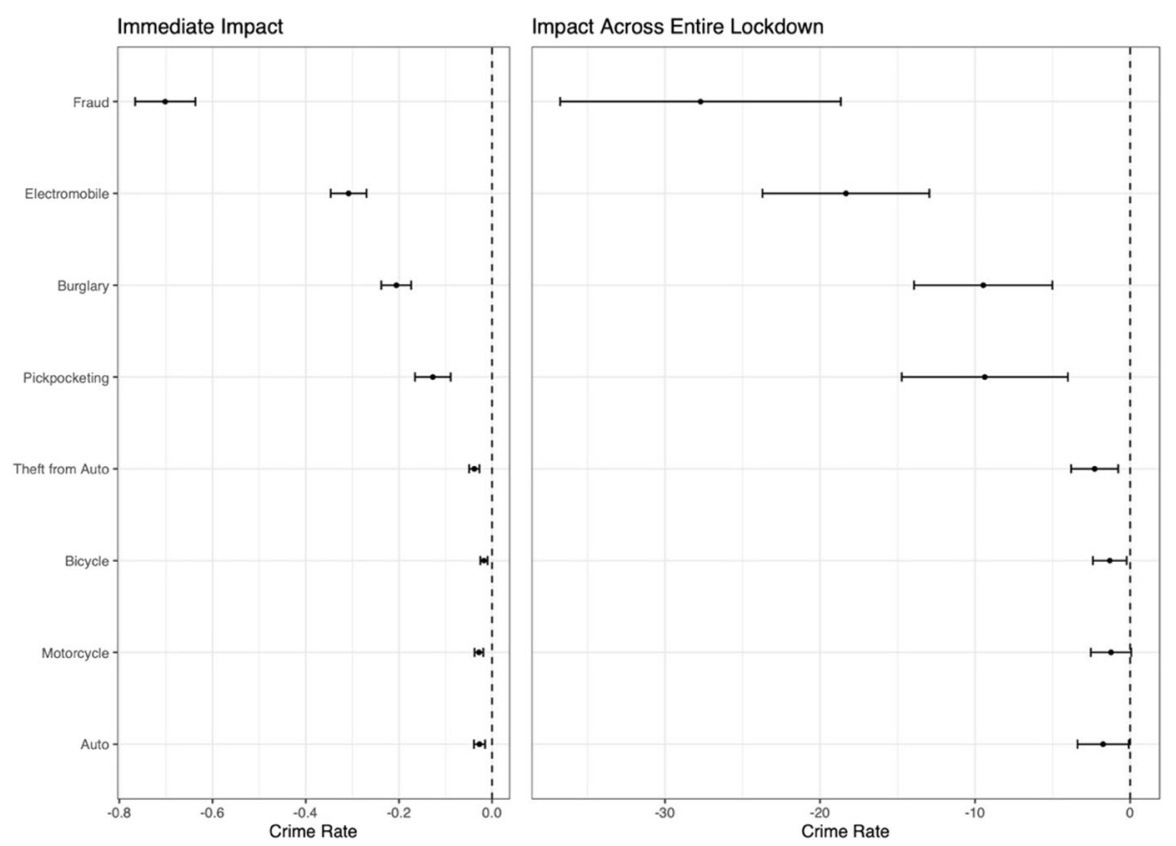

Fig. 7 Regression discontinuity in time (RDiT) coefficients and associated 95\% CIs for the immediate impact (left panel) and the impact across the entire lockdown period (right panel) for each of the eight categories of crime

the potential impact of lockdown on crime, then 8 acquisitive crimes, pickpocketing, residential burglary, electromobile theft, automobile theft, motorcycle theft, bicycle theft, theft from automobiles, cyber-fraud, were analyzed in raw daily counts and the daily rate. By controlling the long-term trend, seasonality, metrological, and harmonic factors, a regression discontinuity in time (RDiT) model was applied to measure the crime variation before and during the lockdown days. Findings show that all acquisitive crimes in the studied city were reduced during the lockdown period, which largely coincides with the theoretical expectations for routine activities theory and meanwhile findings contrary to the hypothesis were also observed (Appendix Tables 2 and 3).

The first is that the traditional property crimes, including automobile theft, electromobile theft, motorcycle theft, bicycle theft, theft from automobiles, pickpocketing, residential burglary, largely followed what would have been expected from the theoretical assumptions underlying routine activity theory in that significant reductions occurred at the beginning of the lockdown days, and then the crimes maintained at relatively low levels until the end of lockdown period. In line with previous findings (Borrion et al., 2020), it can be noticed that property crimes significantly changed during the pandemic period in China. We found that some crime 
types (pickpocketing, residential burglary, and electromobile theft) experienced more reductions than others (automobile theft, motorcycle theft, bicycle theft, theft from automobiles). From this, it can be inferred that lockdown and stay-athome orders have had a different impact on target distribution during the pandemic period. Indeed, the lockdown orders forced people to stay at home for curtailing the spread of the virus; thus, all outdoor activities including urban traffic stopped and the vehicles and bicycles parked on the street or the other public spaces became easy access targets for offenders. At the same time, with people forced to remain at home, guardianship increased thereby enhancing protection for these places (and against crime victimization). Moreover, for electromobile theft, as people living in China were used to dissembling the battery and keeping it at home for safe keeping when they do not use them (Chen \& Lu, 2018), the value of the mobile was lowered and few offenders would likely to steal it. Hence, the enhanced empty houses, lower value of the electromobile, and disappearing outdoor crowds may have reduced offending opportunities.

The exception to this pattern of findings, however, lies with cyber-fraud, the crime type that had among the largest number of cases just prior to the lockdown being instituted. Contrary to previous findings that cyber victimization increased during the lockdown days, the results from this study showed that cyber-fraud in the city decreased like property crimes, which is somewhat contrary to the expectations in the second hypothesis and observations in other works (Buil et al., 2021). However, it is interesting to see the cyber-fraud experienced some resilience. More specifically, at the beginning of the lockdown, cyber-fraud, like other property crimes, experienced significant reductions, but unlike previous research that has had short follow-up periods, our results showed an eventual return to pre-lockdown levels. As a matter of fact, the occurrence of cyber-fraud differs from the property crimes strongly depending on the convergence of potential offenders and suitable targets in physical space and time, it is more determined by the encounter of offenders and victims in online space ${ }^{14}$ as opposed to people living in the "normal rhythm" life. At the beginning of lockdown period, the strict stay-at-home discomforted people and the panic facing the horrible virus and unknown lockdown period led them to focus on their own survival. In that sense, people had to adjust their daily lives from the "normal" to stay-at-home state, switch work/study from offline to online, change their previous freely entertainment/shopping activities to limited styles, etc. Therefore, as people gradually adapted to the new stay-at-home life, their routine activity rhythm was adjusted to a new "normal" state and the time they spent online become more than before, more contacts and opportunities for cyber-fraud were generated.

We believe that our study, among the first to examine crime during the COVID-19 era in China, is an important addition to the knowledge base, especially with respect to the methodological approach using RDiT alongside the

\footnotetext{
14 To be sure, the effect of COVID-19 lockdowns on different types of cyber-fraud, while not as extensively studied as more traditional street crimes, has been mixed with some studies finding no changes in cyber victimization (Hawdon et al., 2020) and other studies reporting increases in cyber-fraud victimization more generally (Payne \& Morgan, 2020).
} 
crime data and environmental factors considered, afforded us the opportunity to estimate the variation process during the counterfactual period as opposed to providing a simple estimate of a change in the mean count (or rate). In so doing, we are able to estimate the net effect of restrictions on crime, from the vantage point of both counts and rates, for M1-city in south China. Some limitations to our study are worth noting. First, our data are based on official records which, while commonplace in research on COVID-19 and crime, still does not capture undetected and unreported crime-which is quite common with respect to cybercrime (and may be why our data show an almost return to pre-lockdown levels by the end of our lockdown observation window). Second, we explored only acquisitive crimes in one city, other crime types such as assault, violence, and drugs await more analysis. Thus, expanding our work in China to other crime types or in more cities for cross comparison would be of interest. Third, our work was unable to perform an in-depth investigation of crime variation across space. The occurrence of crime in place is an attractive phenomenon since the lockdown restrictions required people to stay at home and led to the disruption of routine activities. Given evidence that crime may have spacerelated variability (Campedelli et al., 2020; Felson et al., 2020), it is important to continue work in this area. Lastly, as China goes through openings and lockdowns over time, it is important to continue tracking changes in different types of criminal activity, especially those crimes that often go undetected, such as identity theft and various types of fraud.

Several implications for crime prevention in practice could be inferred from our investigation. The first concerns the observation that most property crimes declined during lockdowns in large part without any police influence. Yet, though not investigated here, some specific types of violence, such as homicide and domestic violence, increased. This suggests that police should consider some differential enforcement or differential allocation during lockdown periods. A second suggestion from our work surrounds cyber-fraud. As our analysis showed that cyber-fraud shows a strong return to pre-lockdown levels, it is incumbent on local, state, and federal agencies to pay significant attention to this crime type and for citizens to take extra precautions when online. 


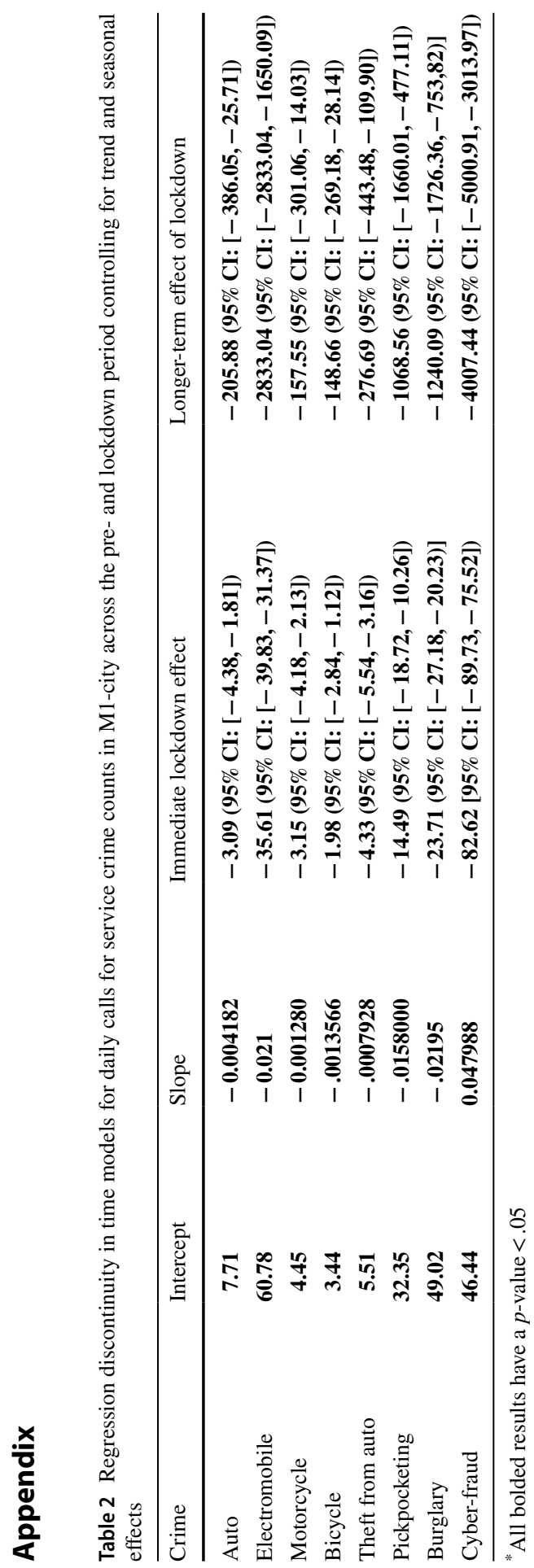




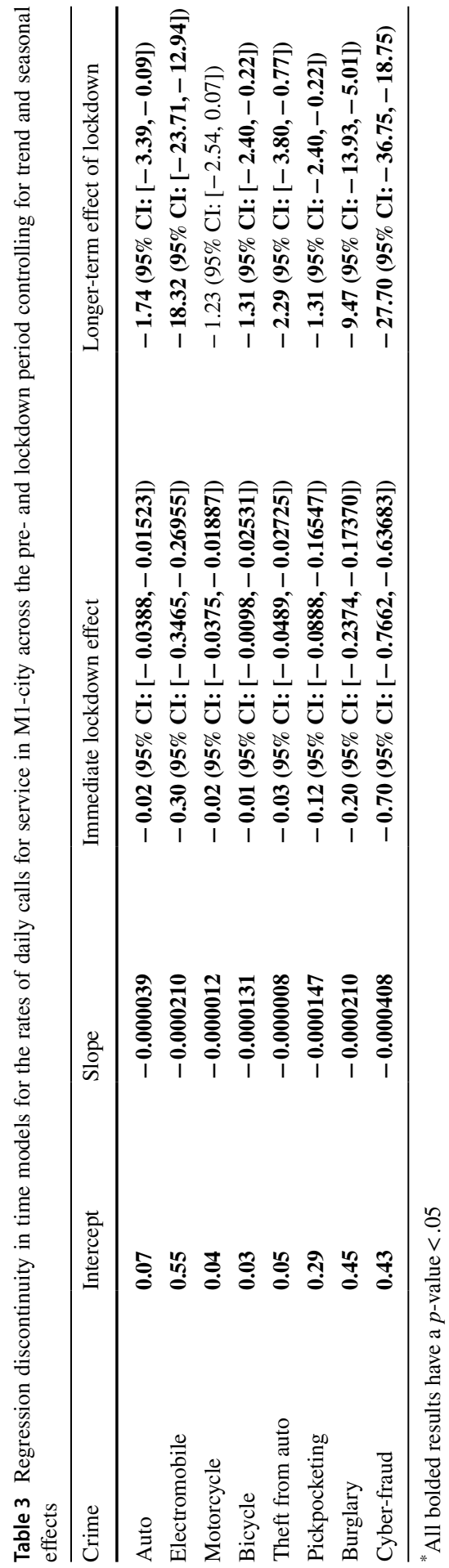


Funding This work was financially supported by MOE (Ministry of Education in China) Project of Humanities and Social Sciences (Project No.20YJAZH009) and Beijing Natural Science Foundation (9192022).

\section{Declarations}

Conflict of interest The authors declare no competing interests.

Research involving human participants and/or animals.

This study reports on the daily count of call for police service. The related data are secondary data. No identifiable information was accessed nor used by the researchers. Strict privacy protection and ethic procedures were followed with M1-city police for the researchers to access the data.

Informed consent.

No primary data were collected for this study. Informed consent concern does not apply.

\section{References}

Ashby, M. P. J. (2020). Initial evidence on the relationship between the coronavirus pandemic and crime in the United States. Crime Science, 9, 6.

Abrams, D. S. (2021). COVID and crime: an early empirical look. Journal of public economics., 194, 104344.

Boman, J. H., \& Gallupe, O. (2020). Has COVID-19 changed crime? Crime rates in the United States during the pandemic. American Journal of Criminal Justice, 45, 537-545.

Boman, J. H., \& Mowen, T. J. (2021). Global crime trends during COVID-19. Nature Human Behaviors. https://doi.org/10.1038/s41562-021-01151-3

Borrion, H., Kurland, J., Tilley, N., et al. (2020). Measuring the resilience of criminogenic ecosystems to global disruption: a case-study of COVID-19 in China. Plos one, 15(10), e0240077.

Buchanan, M., Castro, E. D., Kushner, M., et al. (2020). It's F**ing chaos: COVID-19's impact on juvenile delinquency and juvenile justice. American Journal of Criminal Justice, 45, 578-600.

Buil, G. D., Miro, L. F., Moneva, A., et al. (2021). Cybercrime and shifts in opportunities during COVID19: A preliminary analysis in the UK. European Socities, 23(S1), 47-59.

Bullinger, L. R., Carr, J. B., \& Packham, A. (2021). COVID-19 and Crime effects of stay-at-home orders on domestic violence. American Journal Of Health Economics, 7(3), 249-280.

Campedelli, G. M., Favarin, S., Aziani, A., et al. (2020). Disentangling community-level changes in crime trends during the COVID-19 pandemic. Crime Science, 9, 21.

Chen, P., Shu, X., Yuan, H., \& Li, D. S. (2011). Assessing temporal and weather influences on property crime in Beijing China. Crime Law and Social Change, 55(1), 1-13.

Chen, P., \& Lu, Y. (2018). Exploring co-offending networks by considering geographic background: An investigation of electric bicycle thefts in Beijing. The Professional Geographer, 70(1), 73-83.

Cheung, L., \& Gunby, P. (2021). Crime and mobility during the COVID-19 lockdown: A preliminary empirical exploration. New Zealand Economic Papers. https://doi.org/10.1080/00779954.2020. 1870535

Cohen, L. E., \& Felson, M. (1979). Social change and crime rate trends: a routine activity approach. American Sociological Review, 44(4), 588-608.

Cohn, E. G., \& Rotton, J. (2003). Even criminals take a holiday: Instrumental and expressive crimes on major and minor holidays. Journal of Criminal Justice, 31(4), 351-360.

Dai, M., Xia, Y., \& Han, R. (2021). The impact of lockdown on police service calls during the COVID-19 pandemic in China. Policing: A Journal of Policy and Practice. https://doi.org/10.1093/police/paab0 07

Decker, S. H., Varano, S. P., \& Greene, J. R. (2007). Routine crime in exceptional times: The impact of the2002 winter Olympics on citizen demand for police services. Journal of Criminal Justice, 35, 89-101.

De Livera, A. M., Hyndman, R. J., \& Snyder, R. D. (2011). Forecasting time series with complex seasonal patterns using exponential smoothing. Journal of the American Statistical Association, 106(496), 1513-1527. 
Estévez, S. P. R. (2021). Crime and COVID-19: Effect of changes in routine activities in Mexico City. Crime Science, 10, 15.

Felson, M., Jiang, S., \& Xu, Y. (2020). Routine activity effects of the Covid-19 pandemic on burglary in Detroit. Crime Science, 9, 10.

Gerell, M., Kardell, J., \& Kindgren, J. (2020). Minor COVID-19 association with crime in Sweden, a five week follow up. Crime Science, 9, 19.

Granger, C. W. (1978). Seasonality: Causation, Interpretation, and Implications. In Zellner, A (Eds.), Seasonal Analysis of Economic Time Series (pp. 33-56). National Bureau of Economic Research, Inc.

Halford, E., Dixon, A., Farrell, G., et al. (2020). Crime and coronavirus: Social distancing, lockdown, and the mobility elasticity of crime. Crime Science, 9, 11.

Hawdon, J., Parti, K., \& Dearden, T. E. (2020). Cybercrime in America amid COVID-19: The initial results from a natural experiment. American Journal of Criminal Justice, 45, 546-562.

Hodgkinson, T., \& Andresen, M. A. (2020). Show me a man or a woman alone and I'll show you a saint: changes in the frequency of criminal incidents during the COVID-19 pandemic. Journal of Criminal Justice, 69, 101706.

Jennings, W. G., \& Perez, N. M. (2020). The immediate impact of COVID-19 on law enforcement in the United States. American Journal of Criminal Justice, 45, 690-701.

Kim M T, Leung F (2020). COVID-19 pandemic and crime trends in NSW. Australasian Policing, 12(3). https://search.informit.org/doi/10.3316/informit.435806583384492. Accessed Sept 2020.

Kurland, J., Johnson, S. D., \& Tilley, N. (2014). Offenses around stadiums: A natural experiment on crime attraction and generation. Journal of Research in Crime and Delinquency, 51(1), 5-28.

Kurland, J., \& Johnson, S. D. (2021). The influence of stadia and the built environment on the spatial distribution of crime. Journal of Quantitative Criminology, 37, 573-604.

Kurland J, Piquero A R, Piquero N L (2021). Miami-Dade: a case study of domestic violence arrests during the COVID-19 pandemic. medRxiv. https://doi.org/10.1101/2021.04.20.21255830

Kirchmaier T, Villa L C (2020). COVID-19 and changing crime trends in England and Wales. COVID-19 analysis series. https://www.researchgate.net/profile/Carmen-Villa-Llera/publication/349029677_ Covid-19_Analysis_Series_Covid-19_and_changing_crime_trends_in_England_and_Wales/links/ 601be52d299bf1cc26a089ea/Covid-19-Analysis-Series-Covid-19-and-changing-crime-trends-inEngland-and-Wales.pdf. Accessed Dec 2020.

Langton, S., Dixon, A., \& Farrell, G. (2021). Six months in pandemic crime trends in England and Wales. Crime Science, 10, 6.

Lovell, M. C. (1963). Seasonal adjustment of economic time series and multiple regression analysis. Journal of the American Statistical Association, 58(304), 993-1010. https://doi.org/10.1080/01621 459.1963.10480682

McDonald J F, Balkin S (2020). The COVID-19 and the decline in crime. Available at SSRN: https:// ssrn.com/abstract=3567500. Accessed 10 Apr 2020.

Machimbarrena, J. M., Calvete, E., Fernández-González, L., et al. (2018). Internet risks: An overview of victimization in cyberbullying, cyber dating abuse, sexting, online grooming and problematic internet use. International Journal of Environmental Research and Public Health, 15(11), 2471.

Miyar, J. R. B., Velasco, L. H., \& Murillo, A. S. (2021). Druglords stay at home: COVID-19 pandemic and crime patterns in Mexico City. Journal of criminal justice, 72, 101745.

Mohler, G., Bertozzi, A. L., Carter, J., et al. (2020). Impact of social distancing during COVID-19 pandemic on crime in Los Angeles and Indianapolis. Journal of Criminal Justice, 68, 101692-101692.

Nivette, A. E., Zahnow, R., Aguilar, R., et al. (2021). A global analysis of the impact of COVID19 stay-at-home restrictions on crime. Nature Human Behaviours. https://doi.org/10.1038/ s41562-021-01139-z

Payne J L, Morgan, A (2020). Property crime during the COVID-19 pandemic: a comparison of recorded offence rates and dynamic forecasts (ARIMA) for March 2020 in Queensland, Australia, SocArXiv de9nc, Center for Open Science. https://doi.org/10.31219/osf.io/de9nc

Payne, J. L., Morgan, A., \& Piquero, A. R. (2021). Exploring regional variability in the short-term impact of COVID-19 on property crime in Queensland. Australia. Crime Science, 10, 7.

Piquero, A. R., Riddell, J. R., Bishopp, S. A., et al. (2020). Staying home, staying safe? A short-term analysis of COVID-19 on Dallas domestic violence. American Journal of Criminal Justice, 45(4), $601-635$.

Piquero, A. R., Jennings, W. G., Jemison, E., et al. (2021). Evidence from a systematic review and metaanalysis: Domestic violence during the COVID-19 pandemic. Journal of Criminal Justice. https:// doi.org/10.1016/j.jcrimjus.2021.101806 
Piquero, A. R., \& Kurland, J. (2021). More stringent measures against Covid-19 are associated with lower cases and deaths in Florida and Miami-Dade. The American Journal of Emergency Medicine. https://doi.org/10.1016/j.ajem.2021.04.066

Rosenfeld, R., \& Lopez, E. (2020). Pandemic, social unrest, and crime in US Cities. Council on Criminal Justice.

Stickle, B., \& Felson, M. (2020). Crime rates in a pandemic: The largest criminological experiment in history. American Journal of Criminal Justice, 2020(45), 525-536.

Syamsuddin, R., Fuady, M. I. N., Prasetya, M. D., et al. (2021). The effect of the COVID-19 pandemic on the crime of theft. International Journal of Criminology and Sociology, 10, 305-312.

Zellner, A. (Eds.) (1978). Seasonal analysis of economic time series. National Bureau of Economic Research, Inc

Publisher's note Springer Nature remains neutral with regard to jurisdictional claims in published maps and institutional affiliations.

Peng Chen is an Associate Professor of the School of Informatics Cyber Security at People's Public Security University of China. He received his PhD in Nuclear Science and Technique from Tsinghua University. His research interests include crime pattern analysis, crime prevention, spatial data mining, civil disorder modeling and simulation.

Justin Kurland is the Director of Research for the National Center for Spectator Sports Safety and Security's (NCS4) at The University of Southern Mississippi. He received his PhD in Security and Crime Science from University College London. His research areas include spatio- temporal crime and security pattern analysis, situational prevention, and complex systems.

Alex R. Piquero is Professor and Chair of the Department of Sociology \& Criminology and Arts \& Sciences Distinguished Scholar at The University of Miami and Professor of Criminology at Monash University in Melbourne Australia. He is also editor of Justice Evaluation Journal. His research interests include criminal careers, criminological theory, crime policy, evidence-based crime prevention, and quantitative research methods. He has received several research, teaching, service and mentoring awards and is fellow of both the American Society of Criminology and the Academy of Criminal Justice Sciences. In 2019, he received the Academy of Criminal Justice Sciences Bruce Smith, Sr. Award for outstanding contributions to criminal justice and in 2020 he was recipient of the Lifetime Achievement Award from the Division of Developmental \& Life-Course Criminology of the American Society of Criminology.

Dr Hervé Borrion $(\mathrm{PhD})$ is Deputy Head of Department at the UCL Department of Security and Crime Science. He contributes his expertise in crime modelling and simulation to better understand and address problems as diverse as environmental crime, terrorism and cybercrime. During the last decade, he has been appointed on various advisory boards by the EU Centre for National Infrastructure Protection, MoRiLE harm matrix project, UK Council for Graduate Education and the Open University Centre for Policing Research and Learning. Currently, he devotes most of his research time to support police forces during the COVID-19 crisis. 